\title{
Effect of time and of precursor molecule on the deposition of hydrophobic nanolayers on ethyelene tetrafluoroethylene- silicon oxide substrates
}

\author{
Gabriella Rossi $^{1} \cdot$ Piera Castellano $^{1} \cdot$ Loredana Incarnato $^{1}$
}

Received: 21 September 2015/Accepted: 18 January 2016/Published online: 30 January 2016

(C) The Author(s) 2016. This article is published with open access at Springerlink.com

\begin{abstract}
A method was developed for generating transparent and hydrophobic nanolayers chemisorbed onto flexible substrates of ethylene tetrafluoroethylene-silicon oxide (ETFE-SiOx). In particular, the effect of the deposition time and of the precursor molecule on the nanocoating process was analyzed with the aim of pursuing an optimization of the above method in an industrial application perspective. It was found that precursor molecule of triethoxysilane allowed to obtain better hydrophobic properties on the SiOx surface in shorter times compared to trichlorosilane, reaching the $92 \%$ of final contact angle (CA) value of $106^{\circ}$ after only $1 \mathrm{~h}$ of deposition. The optical properties and surface morphology were also assessed in function of time, revealing that an initial transparency reduction is followed by a subsequent transmittance increase during the self assembly of fluoroalkylsilanes on the $\mathrm{SiOx}$ surface, coherently with the surface roughness analysis data. Encouraging results were also obtained in terms of oleophobic properties improvement of the nanocoated surfaces.
\end{abstract}

Keywords Hydrophobic nanolayer - Self assembled monolayers - Ethylene tetrafluoroethylene-silicon oxide . Fluoroalkylsilanes

\section{Introduction}

Hydrophobic properties may significantly enhance the barrier performance of coating materials in several application fields, such as for instance building industry

Gabriella Rossi

grossi@unisa.it

1 Department of Industrial Engineering, University of Salerno, Via Giovanni Paolo II, 132, 84084 Fisciano, SA, Italy applications and building integrated photovoltaics (BIPV) in particular, helping to address issues like corrosion effects, delamination, loss of electrical performance, etc. Several methods are reported for obtaining hydrophobic or superhydrophobic surfaces. In general, these methods try to imitate the hydrophobic mechanism which can be observed on natural objects such as the lotus leaf. The very high water repellence (superhydrophobicity) that is exhibited by the leaves of the lotus flower allows the dirt particles to be picked up by water droplets due to a complex micro and nanoscopic architecture of the surface on which hydrophobic waxes are imposed. One of these methods for obtaining hydrophobic surfaces is represented by the self assembly of monolayers (SAM) technique using precursor molecules with high hydrophobic properties in order to create protective nano-coatings. In particular, this technique was applied by means of alkylsilanes and (fluoro)alkylsilanes deposition on glass substrates (Altavilla and Ciliberto 2011) and successfully allowed to obtain hydrophobic surfaces. Other methods, that are employed to achieve superhydrophobicity, are based on the introduction of a two-scale roughness (micrometric and nanometric scales), together with chemical functionalization (Xiu et al. 2008; Ling et al. 2009; McConnell et al. 2009; Karunakaran et al. 2011). Although the related works report interesting results in terms of achieved hydrophobicity, they are likely to turn out to be complex and expensive when implemented at industrial level since the proposed methods are based on multi-step processes requiring nonconventional technologies and including high-temperature stages.

In a previous work, we developed a method to obtain flexible and transparent hydrophobic SAM nanocoating using $1 \mathrm{H}, 1 \mathrm{H}, 2 \mathrm{H}, 2 \mathrm{H}$-per-fluorodecyltrichlorosilane as precursor molecule, by means of simple and effective single 
step process carried out at room temperature applied to Polyethylene terephthalate-silicon oxide (PET-SiOx) substrate (Rossi et al. 2014). The hydrophobic nanocoating, which significantly improved the barrier properties of the substrate towards both liquid and gas atmospheric agents (oxygen), also showed a good stability and chemical resistance when applied on both PETSiOx and ETFESiOx substrates (Rossi et al. 2015).

This study analyzes the effect of the deposition time and of the precursor molecule (both $1 \mathrm{H}, 1 \mathrm{H}, 2 \mathrm{H}, 2 \mathrm{H}$-per-fluorodecyltrichlorosilane and $1 \mathrm{H}, 1 \mathrm{H}, 2 \mathrm{H}, 2 \mathrm{H}$ perfluorodecyltriethoxysilane were tested) on the nanocoating of ETFE$\mathrm{SiOx}$ substrate, with the aim of pursuing an optimization of the above method in an industrial application perspective. In particular, the identification of the minimum time needed to achieve a satisfactory hydrophobic behavior would provide information to maximize the performance/cost ratio useful to support the implementation of the process at a manufacturing level.

\section{Materials and methods}

\section{Materials}

The substrates used for the deposition experiments were films of ETFE-SiOx provided by AMCOR as Ceramis CX07-022 SiOx-coated ETFE, with overall thickness of $100 \mu \mathrm{m}$ and thickness of the inorganic coating ( $\mathrm{SiOx}$ ) layer of $\sim 50 \mathrm{~nm}$. The inorganic CERAMIS coating was obtained by heating crystal silicon dioxide by electron beams and by evaporating it as glass vapour, which subsequently condensed on the film forming a very thin glass, flexible layer. ${ }^{1}$ Anhydrous toluene (distilled) was used as solvent. Two different molecules were tested as precursor for the SAM deposition: $1 \mathrm{H}, 1 \mathrm{H}, 2 \mathrm{H}, 2 \mathrm{H}$-per-fluorodecyltrichlorosilane (from now on denominated as $C F A S$ ), and $1 \mathrm{H}, 1 \mathrm{H}, 2 \mathrm{H}, 2 \mathrm{H}$ perfluorodecyltriethoxysilane (from now on indicated as $E F A S$ ), both provided by Alfa Aesar.

\section{Deposition experiments for the preparation of nanocoated samples}

The film samples of ETFE-SiOx were accurately cleaned before the deposition reaction, in order to remove all the impurities from the SiOx surface. The cleaning procedure consisted of subsequent dipping cycles with toluene and distilled water with intermediate drying in $\mathrm{N}_{2}$ flow. The deposition experiments were performed at room

\footnotetext{
${ }^{1}$ Ceramis ${ }^{\circledR}$ Coating Technology-Brochure 2012, accessed at http:// www.amcor.com/businesses/amcor-flexibles/industrial/Ceramis_ Publications.html, on 17th October 2014.

temperature in a glass batch reactor where the substrate was placed. The glassware was preliminary flame dried to remove any trace of water vapour and subsequently a $\mathrm{N}_{2}$ atmosphere was maintained in the reactor. Silane deposition was performed by immersion of the substrate samples (surface area of $80 \mathrm{~cm}^{2}$ ) in $80 \mathrm{ml}$ of a diluted solutions in distilled toluene (1\% v:v of silane) under anhydrous conditions. The effect of the deposition time was investigated for each precursor molecule by performing several experiments and stopping the reaction after different times varying from $2 \mathrm{~min}$ to $21 \mathrm{~h}$. The obtained samples were then cleaned by subsequent dipping cycles with toluene and distilled water with intermediate drying in $\mathrm{N}_{2}$ flow.

\section{Characterization of the nanocoated samples}

FTIR (Fourier transform infrared spectroscopy) measurements were carried out on the pristine and nanocoated samples in the range of $4000-650 \mathrm{~cm}^{-1}$ using a Nexus ThermoNicolet spectrometer equipped with a SmartPerformer accessory for ATR (attenuated total reflectance) analysis. The hydrophobic properties of the obtained samples were assessed by means of static water contact angle (CA) measurements, performed by depositing five drops of distilled water each of $2 \mu \mathrm{l}$ on the sample surface and then calculating the average values on the SiOx side. Experimental measurements were performed with a First Ten Angstrom Analyzer System 32.0 (mod. FTA 1000) according to the standard test method ISO15165-1. The transparency was evaluated by measuring the UV-visible transmittance of the nanocoated and uncoated surfaces from 200 to $800 \mathrm{~nm}$ with the UV-Visible Spectrophotomer $\lambda 800$ Perkin Elmer. The surface morphology was characterized using a Nanoscope V multimode Atomic Force Microscope (Digital Instruments) and the arithmetic average roughness $(\mathrm{Ra})$ and root-mean-square roughness $(\mathrm{Rq})$ values were calculated on scan areas of $10 \times 10 \mu \mathrm{m}$ with the Software Nanoscope Analysis of Bruker (version 1.40). The oleophobic properties were also investigated by means of static oil contact angle measurements performed by depositing 5 drops of $2 \mu \mathrm{l}$ of polyalphaolefinic synthetic oil PAO6 on the sample surface and then calculating the average value.

\section{Results and discussion}

To verify that the condensation reactions successfully occurred on the SiOx layer, ATR-FTIR measurements were carried out on ETFE-SiOx samples, either pristine or nanocoated with SAM of both CFAS and EFAS. In Fig. 1 a change of the spectrum may be noticed for the ETFESiOx system, in the wavenumber range of $1300-1100 \mathrm{~cm}^{-1}$ of 


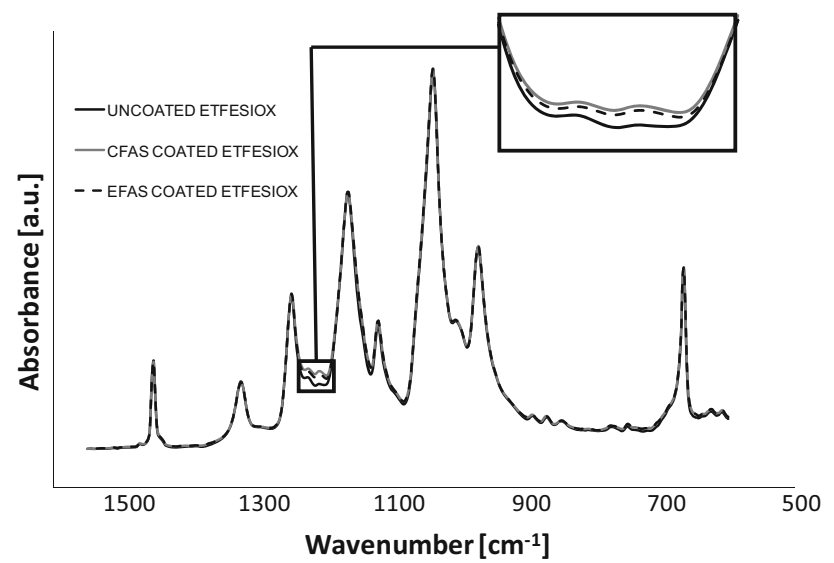

Fig. 1 Infrared spectrum of the following ETFESiOx samples: pristine and coated with SAM of CFAS and EFAS (using a $1 \%$ $\mathrm{v}: \mathrm{v}$ solution of fluoroalkylsilanes in toluene and stopping the reaction after $21 \mathrm{~h}$ ) in the range wavenumber $1500-650 \mathrm{~cm}^{-1}$

nanocoated substrates compared to that of the pristine ETFE-SiOx. In fact, in the spectrum of the nanocoated samples a higher intensity can be clearly observed in the band starting at about $1220 \mathrm{~cm}^{-1}$, more evident for the CFAS coated sample, which is assigned to the $\mathrm{Si}-\mathrm{C}$ linkages appeared after the condensation reaction (Larson et al. 1987; McNaught et al. 1997).

In Table 1 the hydrophobic properties are reported for the nanocoated samples of ETFESiOx obtained with different deposition times. The resulting data suggest that the chemical deposition of both CFAS and EFAS nanolayer successfully changed the $\mathrm{SiOx}$ surface from hydrophilic to hydrophobic, with final average value of CA of $108^{\circ}$ for CFAS, slightly higher but substantially comparable with that of EFAS nanocoated samples $\left(106^{\circ}\right)$.

It may also be observed that the hydrophobic properties undergo a steep enhancement even after very short deposition times, since after only $2 \mathrm{~min}$ a significant increase higher than $300 \%$ is measured for the average CA of both CFAS and EFAS nanocoated surfaces. In particular, two time scales are identified in the growth of CA which after only 2 min reaches $\sim 82-83 \%$ of the final observed value at $t=21 \mathrm{~h}$. These results are coherent with data reported in literature on the growth kinetics of other SAM systems,

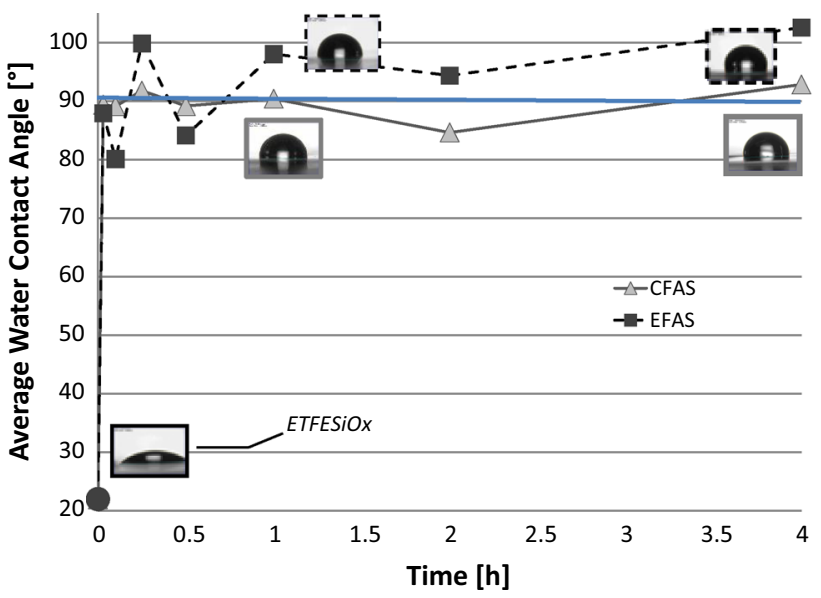

Fig. 2 Static average water CA in function of deposition time and of precursor molecule for the first $4 \mathrm{~h}$

that show a stepwise process rather than a continuous growth path (Schwartz 2001).

Moreover, it can be noticed that although the final average CA value is slightly higher for the CFAS nanocoated surface (Table 1), EFAS nanocoated samples seem to reach more quickly stabilized hydrophobic values, with average CA of $98^{\circ}$ after $1 \mathrm{~h}$ of deposition, as emphasized in Fig. 2, where the achieved hydrophobic properties are shown for the first $4 \mathrm{~h}$ of SAM deposition. From this point of view, EFAS could be a preferential option as precursor molecule for the SAM in an industrial scale-up perspective.

Furthermore, a high standard deviation is measured for deposition times shorter than 60 min (Table 1) when EFAS is used as precursor molecule. These data may indicate a lack of homogeneity of the EFAS SAM in the early stage $(0<t<30 \mathrm{~m})$ in which only a partial coverage occurred of the SiOx surface, as reported also for other similar systems (Lee et al. 2005; Schwartz 2001; Ulman 1996; Schwartz et al. 1992).

Therefore, an analysis of the surface morphology was performed by atomic force microscopy (AFM) to better observe the SAM growth mechanism. The obtained results provide evidence that submonolayer are initially formed (Fig. 3a) as islands of densely packed film molecules with a local structure similar to the complete monolayer (Fig. 3b).

Table 1 Effect of the deposition time and of precursor molecule on the hydrophobic properties: static average water contact angle of pristine and nanocoated ETFESiOx samples

\begin{tabular}{|c|c|c|c|c|c|c|c|c|c|c|c|}
\hline \multirow[t]{2}{*}{$\mathrm{H}_{2} \mathrm{O} \mathrm{CA}\left({ }^{\circ}\right)$} & \multicolumn{11}{|c|}{ Deposition time (min) } \\
\hline & 0 & 2 & 5 & 15 & 30 & 60 & 120 & 240 & 360 & 480 & 1260 \\
\hline \multicolumn{12}{|c|}{ Precursor molecule } \\
\hline CFAS & $22 \pm 5$ & $89 \pm 2$ & $89 \pm 1$ & $92 \pm 0.5$ & $89 \pm 3$ & $90 \pm 3$ & $85 \pm 8$ & $93 \pm 3$ & $97 \pm 5$ & $106 \pm 3$ & $108 \pm 5$ \\
\hline EFAS & $22 \pm 5$ & $88 \pm 11$ & $80 \pm 12$ & $100 \pm 4$ & $84 \pm 8$ & $98 \pm 5$ & $94 \pm 1$ & $103 \pm 4$ & $102 \pm 4$ & $103 \pm 1$ & $106 \pm 2$ \\
\hline
\end{tabular}



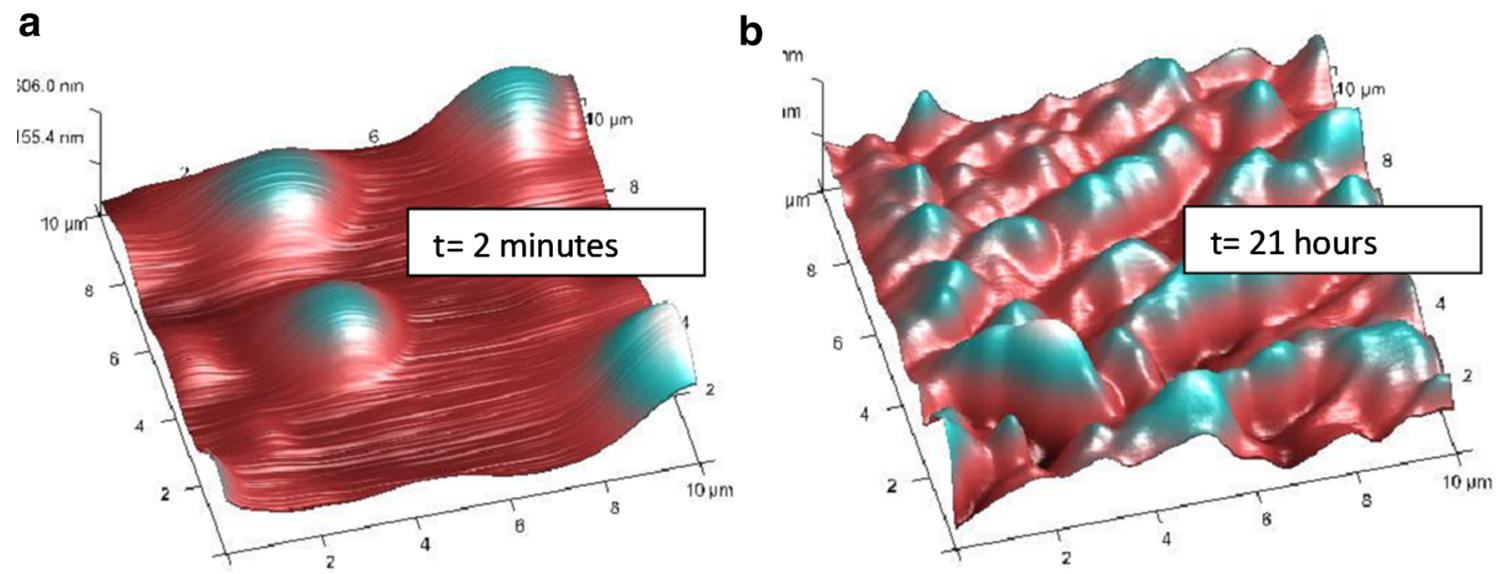

Fig. 3 AFM images with scan area $10 \times 10 \mu \mathrm{m}$ of ETFESiOx sample coated with SAM of EFAS after deposition times of: a 2 min and b $21 \mathrm{~h}$

Table 2 Effect of deposition time and of precursor molecule choice on the surface morphology of uncoated and nanocoated ETFESiOx samples: arithmetic average roughness $(\mathrm{Ra})$ and the root mean square roughness $(\mathrm{Rq})$

\begin{tabular}{llr}
\hline Deposition time $(\min )$ & $\mathrm{Ra}(\mathrm{nm})$ & $\mathrm{Rq}(\mathrm{nm})$ \\
\hline 0 & 21.75 & 26.95 \\
Precursor molecule: CFAS & & \\
2 & 81.25 & 109.45 \\
1260 & 17.45 & 23.03 \\
Precursor molecule: EFAS & & \\
2 & 89.40 & 115.75 \\
1260 & 23.60 & 30.25 \\
\hline
\end{tabular}

In Table 2 the arithmetic average roughness $(\mathrm{Ra})$ and the root mean square roughness $(\mathrm{Rq})$ values are reported for uncoated and nanocoated ETFESiOx samples. It may be seen that a roughness increase, occurring in the first step of the SAM growth for both EFAS and CFAS, is followed by a surface smoothing phenomenon observed after longer deposition times, which may be attributed to a higher coverage of the SiOx layer with the SAM.

Moreover, transmittance measurements were carried out in the UV-Visible range on the nanocoated substrates of ETFESiOx for assessing the effect of the SAM on the transparency of the film samples.

Figure 4 shows that the EFAS nanolayer did not affect the optical properties of the substrate, while a slight transparency reduction was observed after the SAM deposition when CFAS is used as precursor.

Thus, it is worth to point out that in the context of a photovoltaic application the EFAS molecule clearly represents the best choice as precursor for the SAM, since it allows to maintain the initial transparency level of the substrate.

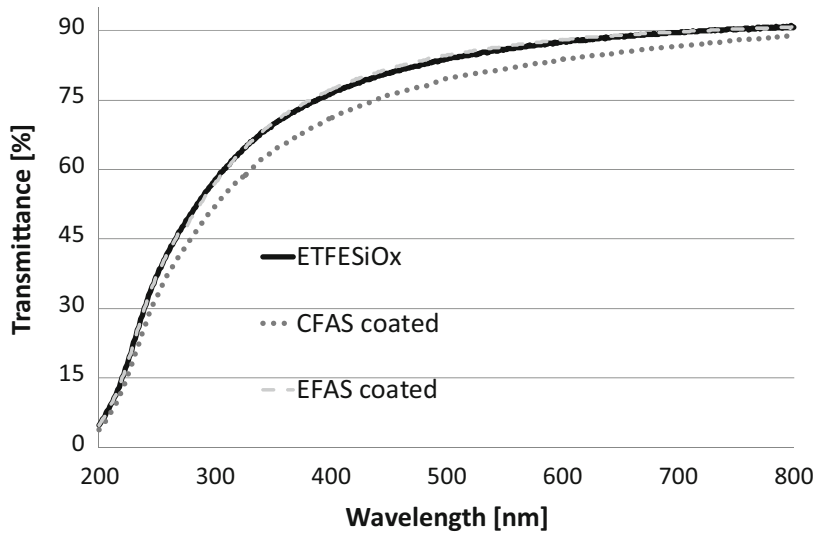

Fig. 4 Effect of the precursor molecule on the optical properties: percent transmittance of pristine substrates and of nanocoated ETFESiOx samples with CFAS and EFAS after $21 \mathrm{~h}$ of deposition

If the optical properties are assessed in function of the deposition time for each precursor molecule (Fig. 5), it may be noticed, more evidently for CFAS, that after $2 \mathrm{~min}$ the nanocoated ETFSiOx undergoes a higher transparency reduction, which is subsequently attenuated for longer deposition times. These results are well correlated with the surface roughness data obtained by AFM analysis, which indicated a not monotonous trend for the surface roughness in function of the deposition time (Table 2).

In fact, transparency and roughness are competitive properties and the transparency reduction is a consequence of the scattering effect (Gouesbet and Gréhan 2011) occurring when the wavelength of the incident light becomes comparable with the protrusions dimension. Thus, the decrease of transmittance found after 2 min of deposition may be linked to the modification of the surface morphology which undergoes a quick roughness increase in the early stage of self-assembly (Table 2). 

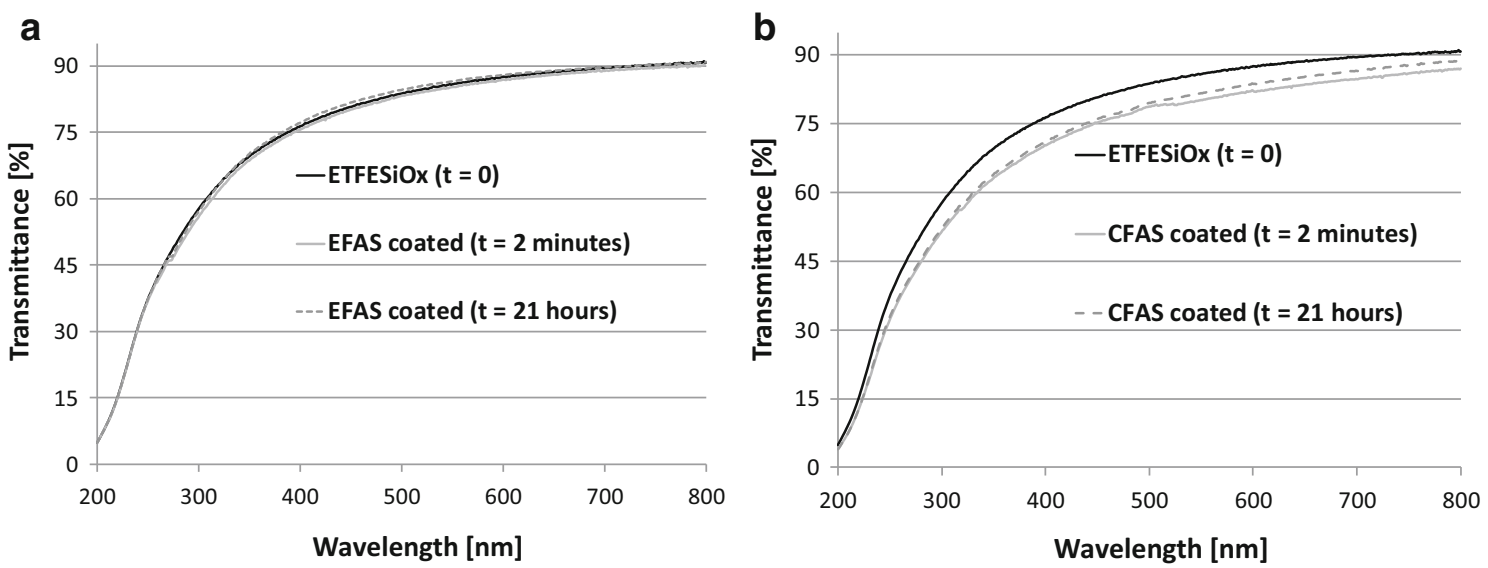

Fig. 5 Effect of deposition time on the optical properties: percent transmittance in the UV-Visible range of nanocoated ETFESiOx substrates with SAM of a EFAS and b CFAS

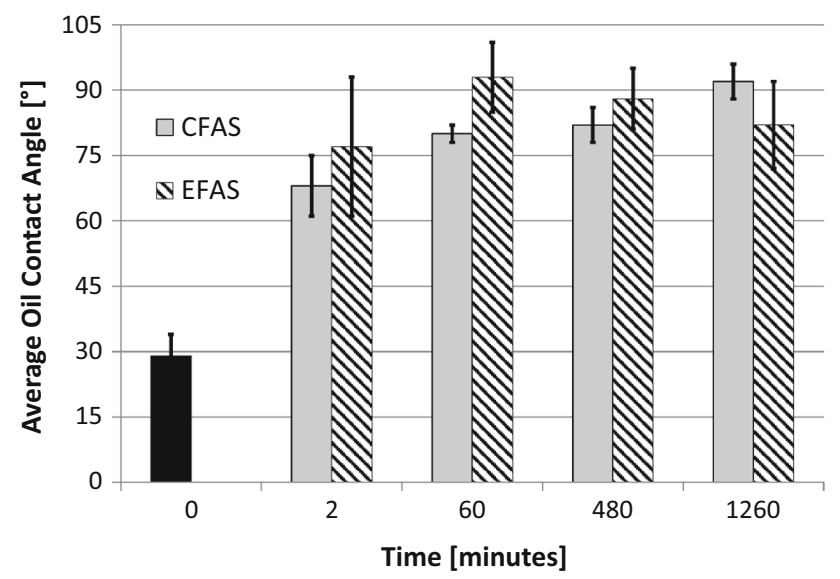

Fig. 6 Static average oil CA in function of deposition time and of precursor molecule (CFAS/EFAS) for pristine and nanocoated ETFESiOx samples

Oleophobic properties were also evaluated for the nanocoated samples and the obtained results are shown in Fig. 6, where an increase of the oil CA may be clearly observed after the SAM deposition for both precursor molecules CFAS and EFAS. A continuous growth trend was measured for CFAS, while the data related to EFAS nanocoated surfaces present some fluctuations. These preliminary results will be further investigated in future research activities.

If all the obtained data are compared in a synoptical framework, EFAS would result the preferential choice as precursor molecule since it allows obtaining higher stable hydrophobic properties after shorter deposition times, at room temperature. Furthermore, the optical properties of the EFAS nanocoated films are better if compared to CFAS and besides no significant cost differences exist between the two fluoroalkylsilanes. In addition, it should be also considered that CFAS leads to the formation of hydrochloric acid in an intermediate reaction step (Rossi et al. 2014), which may represent a drawback in terms of environmental and safety hazard.

Moreover, from an analysis of the discussed results, the minimum time that is necessary to achieve satisfactory modification of the ETFESiOx substrate may be deduced. Specifically, this time can be assumed equal to $1 \mathrm{~h}$, after which stable hydrophobic behavior is observed for the EFAS nanocoated samples which reaches $\sim 92 \%$ of the final $\mathrm{CA}$ value measured after $21 \mathrm{~h}$ of deposition.

\section{Conclusions}

The results demonstrated that the proposed method for obtaining transparent and hydrophobic nanolayers on ETFE-SiOx substrates may be optimized by selecting an alternative precursor molecule, namely $1 \mathrm{H}, 1 \mathrm{H}, 2 \mathrm{H}, 2 \mathrm{H}$ perfluorodecyltriethoxysilane, and that satisfactory modification of surface are achieved even after only $1 \mathrm{~h}$ of SAM deposition, reaching $\sim 92 \%$ of the final CA value that is obtained after $21 \mathrm{~h}$.

These data will be further investigated in future research activities and pave the way for obtaining barrier films with significantly improved resistance to the atmospheric degradation phenomena, which may be useful in several applicative fields such as for instance BIPV.

Open Access This article is distributed under the terms of the Creative Commons Attribution 4.0 International License (http:// creativecommons.org/licenses/by/4.0/), which permits unrestricted use, distribution, and reproduction in any medium, provided you give appropriate credit to the original author(s) and the source, provide a link to the Creative Commons license, and indicate if changes were made. 


\section{References}

Altavilla C and Ciliberto E (2011) Surface modification induced by cleaning and protective treatments in cultural heritage materials: an XPS APPROACH, Altavilla and Ciliberto Eds. Nova Science Publishers ISBN-10: 161324651X. Chapter 5. pp 45-52

Ceramis ${ }^{\circledR}$ Coating Technology-Brochure 2012 accessed at http:// www.amcor.com/businesses/amcor-flexibles/industrial/Ceramis_ Publications.html. Accessed 17th October 2014

Gouesbet G and Gréhan G (2011) Generalized Lorenz-Mie Theories, Springer, Berlin Heidelberg, (978-3-642-17193-2978-3-64217193-2.)

Karunakaran RG, Lu C, Zhang Z, Yang S (2011) Highly transparent superhydrophobic surfaces from the coassembly of nanoparticles ( $\leq 100 \mathrm{~nm}$ ). Langmuir 27:4594-4602

Larson GL, Arkles B, Anderson R (1987) Silicon compounds, register and review. Petrarch Systems, Bristol

Lee BH, Myung M, Sung M (2005) Effect of island size on the packing density in the early stages of alkylsilane-based monolayer self assembly. Bull Korean Chem Soc 26:127-130

Ling XY, Phang IY, Vancso GJ, Huskens J, Reinhoudt DN (2009) Stable and transparent superhydrophobic nanoparticle films. Langmuir 25:3260-3263
McConnell MD, Yang S, Composto RJ (2009) Covalent nanoparticle assembly onto random copolymer films. Macromolecules 42:517-523

McNaught AD, Wilikinson A, Jenkins A (1997) IUPAC Compendium of chemical terminology. Blackwell Scientific Publications, Oxford, UK

Rossi G, Altavilla C, Scarfato P, Ciambelli P, Incarnato L (2014) Deposition of transparent and flexible nanolayer barrier on standard coating materials for photovoltaic devices. Surf Coat Tech 239:200-205

Rossi G, Altavilla C, Scarfato P, Ciambelli P, Incarnato L (2015) Durability study of transparent and flexible nanolayer barrier for photovoltaic devices. Polym Degrad Stabil 112:160-166

Schwartz DK (2001) Mechanisms and kinetics of self-assembled monolayer formation. Annu Rev Phys Chem 52:107-137

Schwartz DK, Steinberg S, Israelachvili J, Zasadzinski JAN (1992) Growth of a self-assembled monolayer by fractal aggregation. Phys Rev Lett 69:3354

Ulman A (1996) Formation and structure of self-assembled monolayers. Chem Rev 96:1533-1554

Xiu Y, Zhang S, Yelundur V, Rohatgi A, Hess DW, Wong CP (2008) Superhydrophobic and low light reflectivity silicon surfaces fabricated by hierarchical etching. Langmuir 24:10421-10426 